SPECIALARTICLE

\title{
Indeterminate leprosy. A passing phase in the evolution of leprosy
}

\author{
V N SEHGAL* \& G SRIVASTAVA \\ Department of Dermatology and Venereology, Maulana Azad \\ Medical College and Associated LNJPN\& GB Pant Hospitals, New \\ Delhi 110002, India
}

\section{Accepted for publication 5 January 1987}

\begin{abstract}
Summary The diagnosis of leprosy at an early stage, when the signs and symptoms are still equivocal, is a matter of continuing difficulty to the clinician. This is the case in indeterminate leprosy. The physicians' dilemma is further compounded by the different schools of thought regarding the clinical features and treatment practice of this form of leprosy. This paper reviews the subject of indeterminate leprosy and attempts to shed some light on a controversial entity.
\end{abstract}

\section{Historical}

The term 'indeterminate' was initially proposed in 1948 at The International Congress of Leprosy, Havana, and officially adopted at the next Congress Meeting in Madrid (1953). It replaced the previous term, 'uncharacteristic', of the South American Classification, and covered all flat macules of leprosy either hypochromic, erythemato-hypochromic or erythematous, hypo-anasthetic or anasthetic, usually with no associated nerve enlargement, and few in number. Subsequently, the above definition was retained at the International Leprosy Congress in Tokyo (1958). However, The Round Table meeting on indeterminate leprosy in the following conference in Rio ${ }^{1}$ redefined this entity as comprising hypochromic and/or erythematous macules with well-defined/poorlydefined borders, frequent impairment of sensation, usually unaccompanied by palpable thickening of regional/peripheral nerves, and usually varying in size, number and location. It further added that bacilli are usually absent, and that there is a non-specific histology. The International Leprosy Congress in Mexico City (1978) $)^{2}$ also approved the definition of the earlier conference.

The First Report of the WHO Expert Committee on Leprosy (1953) included the maculoanasthetic lesions of Indian classification in indeterminate group. Nevertheless, various workers ${ }^{3.4}$ emphasized that maculo-anasthetic lesions are distinct from the indeterminate ones. It has also been suggested that the polyneuritic group of Indian classification should be included in the indeterminate group, and that the latter then should be divided into 2 groups, namely, 1, macular indeterminate; and 2 , neuritic (or polyneuritic) indeterminate. ${ }^{5}$

* Correspondence: Professor V N Sehgal, A/6 Panchwati, Delhi 110033, India 


\section{Definition and nomenclature}

The statement of Pettit ${ }^{6}$. . . if all of Dr Brownes" ${ }^{7}$ cases cleared without treatment, while most of Dr Fajardo's ${ }^{8.9}$ patients need 3 years' treatment to be moderately improved, they are not talking about the same thing. . ' indicates that indeterminate leprosy cannot always be delineated precisely and that it is necessary to add clinical, bacteriological, histopathological and immunological features in order to use this classification clearly. In Madrid classification, indeterminate leprosy is defined as a benign form, relatively unstable, seldom bacteriologically positive, presenting flat-skin lesionshypopigmented and erythematous, which may evolve towards the lepromatous or tuberculoid form, or may persist unchanged indefinitely. Lepromin reaction is negative to positive. Neuritic manifestations, more or less extensive, may develop in cases which have persisted for long periods. But some workers ${ }^{10}$ classify as indeterminate all flat lesions not showing typical tuberculoid features, i.e. clear-cut, well-defined limits, with convincing loss of at least 2 of the 3 types of superficial sensitivity, or enlargement of a superficial nerve supplying the area. Contreals ${ }^{\prime \prime}$ defines indeterminate leprosy as those relatively benign cases, almost always negative for bacilli, who have flat-skin lesions - almost always hypochromic, sometimes erythematous, with evident changes in sensitivity, non-specific histology, and a usually negative lepromin test. He adds a possibility of existence of pure neural forms in the entity.

Indian Leprologists' Classification ${ }^{12}$ also offers a separate group for indeterminate. However, the Ridley-Jopling scale ${ }^{13}$ has no place for indeterminate as an entity. Ridley ${ }^{14}$ clarifies an important point about the macular lesions in that they are less evolved than other sorts of lesions of leprosy, which makes them less easy to classify with certainty, and an 'indeterminate' macule is one that cannot be 'determined' or classified. He further adds that the lesions are more often indeterminate histologically than clinically, because a small granuloma may not be found and is frequently missed.

The diversity of the definition is also seen in parts of Africa, where indeterminate has been regarded as a variegated group which includes not only the early lesions whose polar tendency is not yet apparent, but also the secondary polyneuritic in which the residual scarring of cutaneous manifestations is of no diagnostic value. ${ }^{15}$ In South East India, the term is applied to multiple lesions, of ten symmetrical and not infrequently confined to extremities where bacilli can usually be demonstrated by standard techniques, and up to 60-70\% may eventually become lepromatous. ${ }^{15}$

Before the indeterminate was assigned in Havana (1948), such cases were lumped in the ever obliging category of 'Incharacteristic' (uncharacteristic) leprosy. Arnold ${ }^{16}$ gives an interesting account of the background negotiations involving the classification which took place during the 5 th International Leprosy Congress at Havana. The Latin American proposal to use the term, incaracteristico (1), had led to confusion since the English translation of 'uncharacteristic' did not match the symbol I. Arnold then suggested the English translation of 'indeterminate', and the Spanish translation subsequently used the word 'indeterminado (indifferentiado)'. In the next Congress at Madrid (1953), the term, indeterminate, was officially adopted.

Rabello, ${ }^{17,18}$ however, prefers to call 'I' as, immature or undifferentiated, and advises changing in English the capital letter 'I' for ' $U$ '. Further, he stresses that in no case should it be used synonymous with borderline since this could lead to confusion between the pregranulomatous forms that are truly 'I', and the advanced forms of granulomatous type which show instability.

\section{Epidemiology and incidence}

Indeterminate leprosy is frequently seen in parts of the world where leprosy is endemic or hyperendemic. This type has been described as forming a substantial percentage of all cases in some parts of the world. Bechelli ${ }^{19}$ reported the incidence of 'I' as high as $76 \%$ in a total of 1914 leprosy 
patients. A significant rate of prevalence as well as incidence of indeterminate leprosy is also documented by other investigators. ${ }^{11.20} 23$.

Most of the cases of indeterminate leprosy invariably cluster amongst young children. Noussitou, ${ }^{21}$ while executing a large school survey in Burma comprising of 350,798 students, reported $65.8 \%$ indeterminate leprosy in a total of 6990 leprosy cases. Yet another well-documented report ${ }^{24}$ recorded a $30 \%$ incidence of ' $\mathrm{I}$ ' in all children with leprosy, the prevalence being $14 \cdot 2 \%$ higher amongst the contacts. Various other research workers ${ }^{11.201 .22 .23}$ also substantiate a pooling of indeterminate cases in children.

\section{Pathogenesis}

Indeterminate skin lesions are regarded by many ${ }^{25-28}$ as the initial clinical presentation of leprosy. In chronological order, they are the earliest to appear, and so may be the first manifest sign of the disease. ${ }^{25.29}{ }^{37}$ As soon as the infecting organisms invade the skin, they are taken up by histiocytes. However, if they penetrate terminal nerve twigs, Schwann cells engulf them. A silent phase of the infection thus ensues, which either eradicates the infection, or passes into the indeterminate phase which may follow its course of evolution and involution, or may directly blossom out into the 'determinate' forms of leprosy (Figure 1). Ridley ${ }^{38}$ describes first stage and second stage indeterminate lesions.

First stage indeterminate lesions: A small number of immunologically undetected leprosy bacilli produce no response, and thus no disease. If the immunity of the patient is good enough to detect and destroy the bacilli before they start multiplying, there never will be any disease. If immunity is slightly less good, a clump of bacilli will become established and multiply to the point at which they become detected. A few lesions will develop, but because bacilli are few and hypersensitivity has not yet developed, the response will be mild and non-specific, indeterminate. Such lesions will probably heal spontaneously. If immunity is still less good, bacilli will multiply further, before they are detected immunologically, and the disease will not be self-healing. However, if the immunity is very low, bacilli will get disseminated before they are detected. ${ }^{38}$

Second stage indeterminate lesions: When the disease becomes slightly more advanced, its character becomes apparent clinically from the size and distribution of the lesions, the nature of their edges, degree of erythema, with subtle sensory changes. Their characteristics are largely due to the vascularity and non-specific infiltrate. ${ }^{38}$

Skinsnes ${ }^{29}$ believes that akin to 'first infection' and 'second infection' type tuberculosis, leprosy may also exhibit these stages. 'First infection' represents the course of the disease prior to the development of cellular immunity and delayed type hypersensitivity to tubercle bacilli and its products. On a similar analogy, this first type of response in leprosy should be expected prior to the development of characteristic features that set apart lepromatous and tuberculoid leprosy. It is, therefore in very early cases, indeterminate, that the 'first infection' type of inflammation would be established. ${ }^{29}$

\section{Clinical features and course}

The patient usually is a child, presenting with one or more macules-hypopigmented or faintly erythematous. The outer edges of such macules vary from ill-defined to well-defined, but are usually somewhere between the two. ${ }^{39}$ Sensory loss may be absent or mild, and the nerve feeding the patch as well as regional nerves may not be palpable (Table 1). Sweating and hair growth remains unaffected unless the lesions are very old. Ordinarily there is a single macule, but if there are several, they are distributed asymmetrically. The usual sites are the regions of the body normally covered with clothes, buttocks, trunk and proximal parts of extremities. ${ }^{34,39}$ 


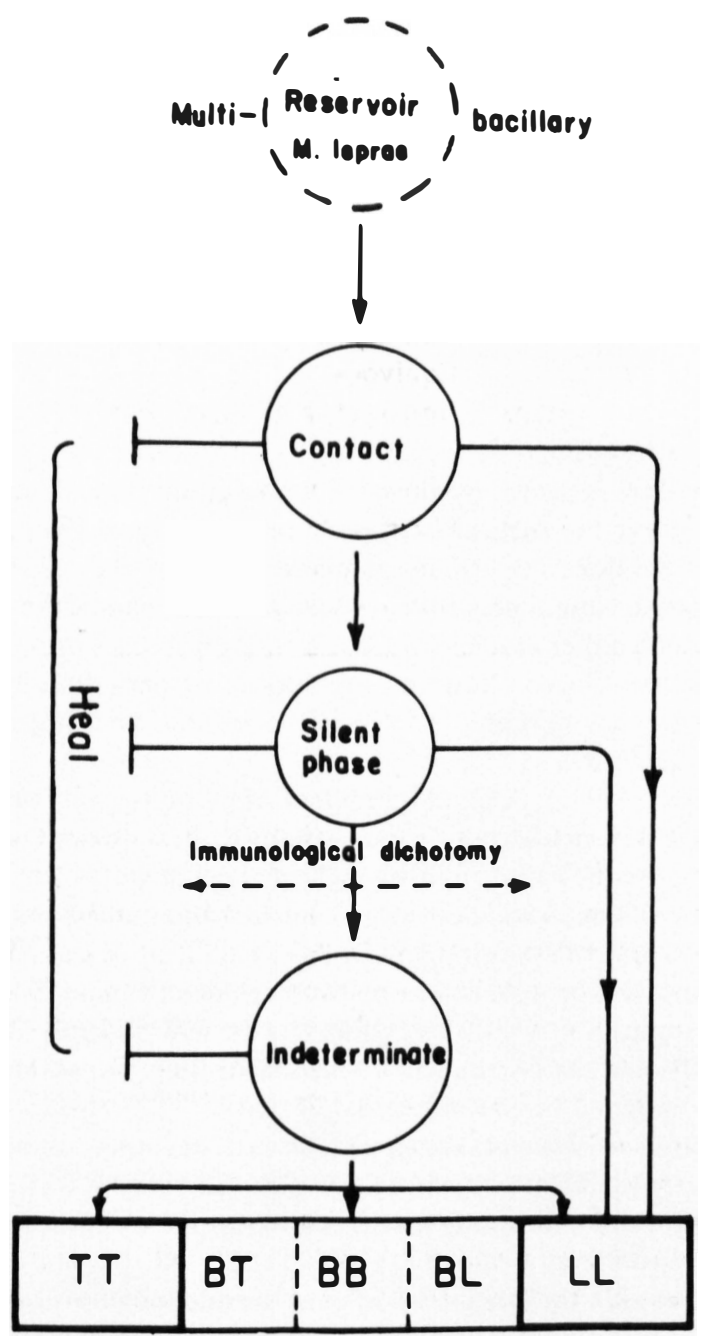

Figure 1. Position of indeterminate leprosy in the natural history of leprosy.

Due to their ambiguous, non-irritating, symptomless nature, indeterminate lesions are frequently overlooked. Often, these people do not report to medical personnel for advice. ${ }^{25.34,40}$ This may especially be so in the developing countries where people may totally neglect the situation. The problem is further compounded by the fact that ' $I$ ' is said to constitute a substantial majority of the leprosy patients in certain communities and in endemic and hyperendemic areas. This warrants regular whole population surveys in these areas.

Indeterminate lesions follow a variable course. The lesions may remain unchanged for a long time, may disappear spontaneously without progress, or may progress and evolve into wellrecognized, 'determinate' (determined) forms of leprosy. ${ }^{8.25 .28 .41}{ }^{43}$ Perhaps three-fourths of all indeterminate lesions heal spontaneously..$^{10}$ Cases which persist for long periods are stated in the older literature to be liable to develop, more or less extensive neuritic manifestations. ${ }^{44}$ The cases which advance towards the 'determinate' forms, may reflect either a tuberculoid or lepromatous propensity. There is a solitary report ${ }^{45}$ in which indeterminate leprosy evolved in histoid leprosy. 
Table 1. Clinical features of indeterminate leprosy ${ }^{10.25}$

$\begin{array}{ll}\text { Type } & \text { Macule } \\ \text { Colour } & \text { Hypopigmented/erythematous } \\ \text { Margins } & \text { Vague and ill-defined } \\ \text { Infiltration } & \text { Absent } \\ \text { Surface } & \text { Not dry, may be smooth } \\ \text { Sensations } & \text { Equivocal } \\ \quad \text { Temperature } & \text { Impaired, with exceptions } \\ \text { Light touch } & \text { Frequently not impaired } \\ \text { Pain } & \text { Impaired, with exceptions } \\ \text { Nerve thickening } & \text { Usually absent, rarely+ } \\ \text { Number } & \text { One, few or a few } \\ \text { Location } & \text { Buttocks, thighs, trunk, extensors } \\ \end{array}$

\section{Histopathology and bacteriology}

Histology of such lesions may often provide a clue to leprosy, and thus forms an inseparable tool in its diagnosis. The lesion usually shows foci of a chronic inflammatory cellular exudate, mainly arranged around the fine nerve fibres in the plexuses of the dermis. These fibres are abundant around the pilo-sebaceous apparatus and the vasculature of the dermis. Cellular exudate is usually concentrated as strands or groups of cells around these structures. Exudate is comprised of small round cells-lymphocytes, histiocytes, plasma cells, and very occasionally eosinophilic, basophilic and neutrophilic polymorphonucleocytes. ${ }^{5}$ As a granuloma has not yet developed, indeterminate lesions occupy not more than one-twentieth of the dermis. ${ }^{46.47}$ However, Liu et al. ${ }^{48.49}$ verified the above findings in only $20 \%$ of their study material.

Although bacilli are difficult to demonstrate, a thorough and careful search of several serial sections is imperative for a justifiable diagnosis of ' $\mathrm{I}$ ', as it may reveal one or a few acid-fast rods in a nerve twig, arrector pilorum muscle or sub-epidermal zone. Bacilli in nerves, except when they are in clumps, lie parallel to the axons. Therefore they can sometimes be demonstrated if the nerves are cut longitudinally, when they will be seen lying lengthwise. Bacilli in subepidermal zone usually lie parallel to the epidermis just below the basal cell layer. Sometimes they may point between two basal cells or may be seen engulfed by a macrophage. In arrector pilorum muscle, they are often oriented haphazardly. The more the sections are examined, the greater is the chance for finding the bacilli. ${ }^{30.46,47}$ Often, bacilli may be detected at a site where there is no cellular reaction, while elsewhere in the section there may be cellular exudate with no bacilli. ${ }^{38}$

Browne ${ }^{41}$ advises that if every 5 th section is examined and a small dermal nerve fibril is traced, sooner or later a single AFB or a small clump may be discovered.

Hasselman ${ }^{50}$ reports a pronounced narrowing of the stratum spinosum of epidermis, with flattening of rete pegs as an early finding in these lesions. However, epidermal changes do not form a significant feature of indeterminate leprosy ${ }^{48}$ Hyaline changes, occurring in dermal nerves, have also been reported. ${ }^{51} \mathrm{~A}$ correlation between the clinical features and the histopathologic characteristics may sometimes be lacking, i.e. a clinically indeterminate lesion may show tuberculoid granuloma and vice versa. Sehgal et al. ${ }^{52}$ recorded an indeterminate histology in 5 patients clinically diagnosed as BT.

Although indeterminate histology is characteristically found in an indeterminate macule of leprosy, yet it may also be found in early maculo-anasthetic (macular tuberculoid) macules. A very 
early lepromatous macule may also show the same, but in such a situation the predominant cytology is likely to be histiocytic and the AFB readily demonstrable. ${ }^{30}$ Residual flat lesions of leprosy may also show a similar histology, and have often been erroneously classified as indeterminate, in the past. ${ }^{30.53}$

\section{Immunology and serology}

The immunological instability of such patients is evident from the name itself. Lepromin reaction, in these patients, may be positive in various degrees, or it may be negative. A favourable outcome of the disease was proposed by Bechelli et al ${ }^{54}$, who performed lepromin test, with $160 \times 10^{6} \mathrm{bacilli} / \mathrm{ml}$, in 209 patients with indeterminate leprosy of less than one year's duration, and demonstrated a strongly positive reaction in a large majority $(61.5 \%)$.

Fliess et al. ${ }^{55}$ recorded no major immunological alteration in lepromin positive 'I' cases, while in lepromin negative individuals they demonstrated certain important immunological alterations, which might indicate these patients may later progress to lepromatous leprosy. Further, they ${ }^{56.57}$ found a correlation between the negative skin tests and depletion of T-lymphocyte population, which may serve as a prognostic parameter.

Although Mitsuda reaction may be negative or positive, it does not remain stationary all the time in indeterminate leprosy. It may show conversion from negative to positive or vice versa. ${ }^{58}$ Thus it forms another important prognostic parameter. ${ }^{8.25557}$

Convit et al..$^{59}$ document an interesting, fruitful observation. They chose Mitsuda negative indeterminate cases, who showed a lack of modification of their clinical and histopathological picture in spite of regular treatment with dapsone and repeated BCG vaccination, for over 3 years. They inoculated these patients with a mixture of BCG and autoclaved armadillo Mycobacterium leprae. A specific change was observed in the form of a positive early and late lepromin test, bacillary clearance and lymphocyte transformation test (LTT). However, Lara and Nolasco ${ }^{28}$ as early as 1956, commented that the lepromin test itself may switch on the immune responses to $M$. leprae, and may explain why repeated lepromin testing may enhance spontaneous recovery of childhood leprosy. Myrvang et al. ${ }^{60}$ believe that these are the cases with strongest immune response to $M$. leprae, as measured by LTT and leucocyte migration inhibition test (LMIT). A negative LTT and LMIT result in 'I', however, does not always signify defective CMI. In most patients, with strictly indeterminate leprosy, a negative LTT and LMIT result may merely indicate that the immune apparatus has not yet started to respond to $M$. leprae to such an extent that these factors can be measured in peripheral blood. This is supported by negative lepromin test and a lack of detectable humoral antimicrobial antibodies. ${ }^{60.61}$

Although the relative number of individuals contracting the disease is low, reports ${ }^{33.37 .62 .63}$ based on the fluorescent leprosy antibody absorption (FLA-ABS) test confirms the age-old conjecture that leprosy is far more infectious than ever thought. Population surveys of various risk-groups, employing FLA-ABS test, may prove invaluable in delineating the high risk groups. A lepromin negative but FLA-ABS positive individual seems to be running a higher risk of developing overt sign and symptoms of leprosy, and thus has to be carefully followed up. A yet more specific serological test demonstrating phenolic glycolipid (PGL-I) by the enzyme-linked immunosorbent assay (ELISA) ${ }^{64}$ is another highlight of the immediate past. However, their utility with regard to indeterminate leprosy has yet to be evaluated.

\section{Diagnosis}

The statement: "If there is one diagnosis that should not be established unless there is absolute certainty, it is that of leprosy ${ }^{343}$ marks the gravity of the situation we are dealing with. If there is the 
slightest doubt in the diagnosis, the patient should be put under observation until further evidence confirms the disease. This will obviate the psychological, social and other damages that would be inflicted on the patient in the event of an incorrect diagnosis. ${ }^{43}$ Keeping this in mind, one has to struggle hard to establish the diagnosis through the available clinical information and serial sections of histopathological specimen. ${ }^{65}$

Pettit $^{\text {t6 }}$ suggests that the diagnosis of indeterminate leprosy can only be made retrospectively when a non-diagnostic lesion has become definitely leprous. He advises that the term 'indeterminate leprosy' be banished from our vocabulary, and that the diagnosis of leprosy should not be made without proof of the disease. ${ }^{65}$

\section{Treatment}

Once the diagnosis of leprosy and an indeterminate classification have been made with absolute confidence, all cases should be treated along the lines advised for paucibacillary leprosy by WHO. ${ }^{67}$ Thus, having received dapsone and rifampicin for a period of 6 months, treatment may be stopped. Patients should then be kept under regular surveillance for a period of time, which, in the present state of our knowledge, should be not less than 3 years after stopping treatment. There is still much to be learned about this controversial form of leprosy and it is of importance to monitor the results of such a regimen with great care.

\section{References}

1 Report of round-table on borderline and indeterminate leprosy. Lepr Rev, 1964; 35: 15-17.

2 Cardama JE. Early lesions. Abstract. Int J Lepr, 1979; 47: 347.

${ }^{3}$ Wade HW. The classification of leprosy. Int J Lepr, 1952; 20: 429.

${ }^{4}$ Dharmendra, Chatterjee SN. A proposed system of classification of leprosy. Lepr India, 1953; 25: 242.

5 Khanolkar VR. Pathogenesis of leprosy. In Leprosy in theory and practice, 2nd ed. Cochrane RG, Davey TF (eds). Bristol: John Wright \& Sons Ltd, 1964, 125.

${ }^{6}$ Pettit JHS. Reply to Dr Browne's Letter to the Editor. Int J Lepr, 1982; 50: 224.

7 Browne SG. Self healing leprosy. Report of 2749 patients. Lepr Rev, 1974; 45: 104-11.

${ }^{8}$ Fajardo TT. Indeterminate leprosy - a 3 year study. Clinical observations. Int J Lepr, 1971; 39: 94-5.

${ }_{9}$ Fajardo TT. Indeterminate leprosy - a five year study, clinical observations. Abstract of Congress Papers 18/156. Int J Lepr, 1973; 41: 576.

10 Noussitou FM, Sansarricq H, Walter J. Leprosy in children. Geneva: WHO, 1976, 19-21.

1 Contreals F. Indeterminate leprosy. Abstract. Int J Lepr, 1963; 31: 600-1.

12 Indian Association of Leprologists - Classification of Leprosy. Lepr India, 1955; 27 : 1.

13 Ridley DS, Jopling WH. Classification of leprosy according to immunity. Int J Lepr, 1966; 34: 255-9.

14 Ridley DS. Modern concepts of the classification of leprosy. Ind J Derm Ven, 1975; 41: 123-8.

15 Browne SG. The variegated pattern of leprosy. Lepr India 1963; 35: 193-9.

${ }_{16}$ Arnold HL. How indeterminate leprosy got its name? Int J Derm, 1981; 20: 393-5.

17 Rabello FE. Hanseriasis: The polar concept as it stands today. Int J Lepr, 1980; 48: 318-21.

18 Rabello FE, Azulay RD, Belda W et al. Again on indeterminate leprosy. Int J Lepr, 1983; 51: 418-20.

${ }_{19}$ Bechelli LM. Indeterminate leprosy in a population survey and in the subsequent follow up of children. Congress Abstract Paper XII. Int J Lepr, 1984; 52: 685. 
20) Reddy BN, Bansal RD. An epidemiological study of leprosy in a rural community in Pondicherry. Ind J Lepr, 1984; 56: 15-23.

${ }_{21}$ Noussitou FM. School surveys in Burma. VIII International Leprosy Congress-Abstract. Int J Lepr, 1963; 31: 565-6.

22 Rao PSS, Karat S. Familial aggregation of leprosy. Lepr India, 1969; 41: 261-5.

${ }^{23}$ Kushwah SS, Govila AK, Kushwah J. An epidemiological study of disability among leprosy patients attending Leprosy Clinic in Gwalior. Lepr India, 1981; 53: 240-8.

${ }^{24}$ Dave DS, Agarwal SK. Prevalence of leprosy in children of leprosy patients. Ind J Lepr, 1984; 56: 615-21.

25 Dharmendra. The indeterminate group. In Leprosy Vol I, 1st ed. Dharmendra (ed). Bombay: Kothari Medical Publishing House, 1978.

26 Binford CH, Meyers WM, Walsh GP. Leprosy. J Am Med Ass, 1982; 247: 2283.

${ }^{27}$ Browne SG. Spontaneous regression of leprosy. Report of 2873 patients. Lepr Rev, 1974; 45: 104-11.

28 Lara CB, Nolasco JO. Self healing or abortion and residual forms of childhood leprosy and their possible significance. Int J Lepr, 1956; 24: 245-63.

29 Skinsnes OK. 'First infection' type leprosy. Int J Lepr, 1969; 37: 310-13.

30) Job CK, Dharmendra. General considerations, histopathology of skin lesions in leprosy. In Leprosy Vol 2, Ist ed. Dharmendra (ed). Bombay: Samant \& Company, 1985, 814, 816.

${ }^{31}$ Desai SD. Spontaneous disappearance of skin lesions; positive smears without lesions. Int J Lepr, 1955; 23: $198-200$.

32 Taylor CE, Elliston EP, Gideon H. Asymptomatic infection in leprosy. Int J Lepr, 1965; 33: 716 27.

${ }^{33}$ Bhardwaj VP, Ramu G, Desikan KV, Katoch K. Extended studies on subclinical infection in leprosy. Ind J Lepr, 1984; 56: 807-12.

${ }^{34}$ Browne SG. Leprosy. Documenta Geigy. London: Leprosy Study Centre, 1984.

${ }^{35}$ Bryceson A, Pfaltzgraff RE. Leprosy, 2nd ed. Edinburgh: Churchill Livingstone, 1979, 13-27.

36 Dharmendra, Iyer CGS, Ramanujam K, Ramu G. Indeterminate and borderline leprosy. Abstract. Int J Lepr, 1963; 31: 602.

${ }^{37}$ Godal T, Negassi K. Subclinical infection in leprosy. Br Med J, 1973; 3: 557.

38 Ridley DS. Skin biopsy in Leprosy. Documenta Geigy, Ciba-Geigy, Basel, 1977.

39 Jopling WH. Hand-book of Leprosy. London: William Heinemann Medical Books Ltd, 1984.

40) Goihman-Yahr M. Leprosy, an overview. Int J Derm, 1982; 21: 423-31.

41 Browne SG. Indeterminate leprosy - a valid clinical concept. Int J Lepr, 1982; 50: 221-3.

42 Puchol JR. Judgement on indeterminate leprosy. Int J Lepr, 1963; 31: 601.

43 World Health Organization. A Guide to Leprosy Control. WHO: Geneva, 1980.

44 Sixth International Congress of Leprosy, Madrid, 1953. Technical Resolutions. Int J Lepr, 1953; 21: 504-16.

45 Ramanujam K, Ramu G. Histoid transformation from unstable forms of leprosy. Abstract of Congress Papers 17/335. Int J Lepr, 1973; 41: 685.

46 Ridley DS. Pathology and bacteriology of the early lesions in leprosy. Int J Lepr, 1971; 39: 21624.

47 Ridley DS. The pathogenesis of the early skin lesions in leprosy. J Path, 1973; 111: 191-206.

48 Liu Z. Histopathology of primary indeterminate leprosy. Chin J Derm, 1980; 13: 129 (In Chinese). Abstract Int J Lepr 1982; 50: 550.

49 Liu T, Yen L, Ye G, Dung G. Histology of indeterminate leprosy. Int J Lepr, 1982; 50: 172-6.

${ }^{50}$ Hasselman CM. Histopathology in early leprosy. Int J Lepr, 1963; 31: 516.

51 Abalos RM. Indeterminate leprosy - a five year study - histological observations. Abstract of Congress Papers 11/258. Int J Lepr, 1973; 41: 640.

52 Sehgal VN, Koranne RV, Sehgal S, Beohar PC, Sharma VK. Correlation of morphological, 
bacteriological, histopathological and immunological features of leprosy. $J$ Derm, 1985; 12: 243-50.

53 Binford CH. The histologic recognition of the early lesions of leprosy. Int J Lepr, 1971; 39: 22530.

${ }^{54}$ Bechelli LM, Garbajosa PG, Gyi MM, Walter J, Tamondong C. Late lepromin reaction in untreated patients with indeterminate leprosy under 21 years old in Burma. Bull WHO, 1973; 48: 113-16.

55 Fliess EL, Bachmann AE, Sasian MC, Ares BR. Immunological studies in patients with indeterminate leprosy. Rev Assoc Argent Microbiol. 1975; 7: 81-5 (In Spanish). Abstract Int J Lepr, 1976; 44: 513.

56 Fliess EL, Carosella ED. T-lymphocyte formation of rosettes in indeterminate leprosy patients. Rev Lepr 1975; 10: 21-5 (In Spanish). Abstract Int J Lepr, 1976; 44: 513-14.

57 Fliess EL, Herrera M, Carosella ED et al. Immunological studies in patients with indeterminate leprosy. Hansenologia Internationalis. 1978; 3: 42-7 (In Spanish). Abstract Int J Lepr, 1980; 48: 93.

${ }^{58}$ Neto AR, deAndrade RSC, deAndrade LHC et al. Evolution of cases in the indeterminate group located at the dispensary of Nova Iguacu from 1949-60. Int J Lepr, 1963; 31: 532.

59 Convit J, Aranzazu N, Pinardi M, Ulrich M. Immunological changes observed in indeterminate and lepromatous leprosy patients and Mitsuda negative contacts after inoculation of a mixture of M. leprae and BCG. Clin exp Immun, 1979; 36: 214-20.

${ }^{60}$ Myrvang B, Godal T, Feek CM. Immune response to $M$. leprae in indeterminate leprosy patients. Acta Pathol Microbiol Scand, 1973; 81B: 615-20.

61 WHO. Meeting of Investigators of Immunological Problems in Leprosy Research. New Delhi, 1972.

62 Abe M, Minagawa F, Yoshina V et al. Studies on the antigenic specificity of $M$. leprae. Purification and immunological characterization of the soluble antigen in leprosy nodules. Int J Lepr, 1972; 40: 107-12.

${ }^{63}$ Abe M, Izumi S, Saito T et al. Early serodiagnosis of leprosy by direct immunofluorescence. Lepr India, 1976; 48: 272.

${ }^{64}$ Cho SN, Yanagihara DL, Hunter SW et al. Serological specificity of phenolic glycolipids from M. leprae and use in serodiagnosis of leprosy. Infect Immun, 1983; 41: 1077-83.

${ }^{65}$ Pettit JHS. Should indeterminate leprosy ever be diagnosed? Int J Lepr, 1981; 49: 95-6.

${ }^{66}$ Pettit JHS. The problem of indeterminate leprosy. Abstract of Congress Papers 18/155. Int J Lepr, 1973; $41: 576$.

67 WHO Study Group. Chemotherapy of leprosy for control programmes. Technical Report Series No. 675. WHO: Geneva 1982. 